\title{
THE PRACTICE-DEPENDENCE RED HERRING AND BETTER REASONS FOR RESTRICTING THE SCOPE OF JUSTICE
}

Saladin Meckled-Garcia

\author{
Presses de Sciences Po (P.F.N.S.P.) | « Raisons politiques »
}

2013/3 N 51 | pages 97 à 120

ISSN 1291-1941

ISBN 9782724633191

Article disponible en ligne à l'adresse :

http://www.cairn.info/revue-raisons-politiques-2013-3-page-97.htm

\section{Pour citer cet article :}

Saladin Meckled-Garcia, «The Practice-Dependence Red Herring and Better Reasons for Restricting the Scope of Justice », Raisons politiques 2013/3 ( $\mathrm{N}^{\circ} 51$ ), p. $97-120$.

DOI 10.3917/rai.051.0097

Distribution électronique Cairn.info pour Presses de Sciences Po (P.F.N.S.P.).

(C) Presses de Sciences Po (P.F.N.S.P.). Tous droits réservés pour tous pays.

La reproduction ou représentation de cet article, notamment par photocopie, n'est autorisée que dans les limites des conditions générales d'utilisation du site ou, le cas échéant, des conditions générales de la licence souscrite par votre établissement. Toute autre reproduction ou représentation, en tout ou partie, sous quelque forme et de quelque manière que ce soit, est interdite sauf accord préalable et écrit de l'éditeur, en dehors des cas prévus par la législation en vigueur en France. Il est précisé que son stockage dans une base de données est également interdit. 


\section{The Practice-Dependence Red Herring and Better Reasons for Restricting the Scope of Justice}

\section{Saladin Meckled-Garcia*}

hould moral principles intended to regulate the actions of people in $\checkmark$ social practices depend in some way on facts about those practices? That is different from asking whether judgements on the morality of those actions should invoke facts. Instead, the question asks whether facts about practices should somehow define the moral principles themselves. On the so-called "practice-dependence" approach to moral methodology, the correct formulation and scope of moral principles that apply to at least some practices depends on facts about those practices. Central amongst these facts is the organising function, or functional role, of a practice that is presupposed by the "shared understandings" of those involved in it. The correct formulation of moral principles for domestic political society, international relations, international human rights discourse, or global trade, will depend on the role played by each of those practices for their participants. The functional role of political society, for example, is some form of cooperation between citizens, whilst the functional role of international society is some form of cooperation between states. It makes sense, then, that principles of fairness between individuals should guide domestic societies, but not international relations. The consequences of such a view are far-reaching for people's rights and duties. We do not have the claim internationally, as we do domestically, that institutional agents guide their actions so as to have equal or fair effect on individuals' life chances.

In this paper, I argue that the central methodological claim of practice-dependence theorists is flawed, even if some of their substantive conclusions are not. This is because the view fails an important test for any moral theory, the "justifiability test". Any moral account, methodological or otherwise, that has implications for the rights people must respect or the duties they must bear should be justifiable to those persons in terms

* Thanks are due to Hugo El Kholi as well as the participants in the workshop "On the Scope of Distributive Justice: Relational and Non-relational Views", Central European University, Budapest, July 2012, for comments and suggestions. 
of a moral value served by that distribution of rights and duties. Yet there is no clear moral value served by making the scope of moral principles, and consequently their distribution of rights and duties, sensitive to facts about practices. As I also show, there are plausible accounts that restrict the scope of distributive justice to the institutions of political community, but by reference to value-based reasons. Unfortunately, these views have been grouped together with the practice-dependence approach, and the arguments against the former have been taken to cut against these views as well. Those views, however, do not modify moral principles according to facts about practices. They just take morally relevant facts about practices to trigger the applicability of one independently valid moral principle or another. Practice-dependence, then, fails the justifiability test and distracts attention from plausible scope-restricting arguments that do not. I therefore conclude that the practice-dependence approach is a red herring, raising more questions than it answers for the global justice debate.

\section{What is distinctive about practice-dependence?}

In order to highlight what is distinctive about practice-dependence views, I will introduce some key background definitions. I shall take "practice" to refer to behaviour understood in terms of rules, norms, or principles, believed to distinguish the behaviour of participants as a type from other types. The practiced norms of promising, for example, distinguish promising from, say, the practice of friendship with its norms. I shall take a social practice of the kind that concerns me here to be one in which norms assign socially recognised rights, duties, privileges, or costs. Such practices can be described in terms of the point that participants see as the justifying point for their existence, which may differ from the reasons any individual has for adhering to their norms. Individual reasons for adherence may not entail an overall point to the practice, and so may not be candidates for guiding the correct application of its norms. Participants, and observers, may nevertheless disagree on the point of the practice, and consequently on how to correctly follow its norms. How one rationally continues a practice will depend on what one perceives as its point. ${ }^{1}$ Consider the practice of marriage. There are those that see its point as joining people for the sake of procreation while others see it as the expression of commitment to an intimate life partner. These two views about the point of marriage will entail disagreements over whether same-sex marriage is really marriage at all. Whether or not people articulate these views, I am assuming that some such ideas explain their understandings of the norms of a practice.

Nothing in the way in which I have described a social practice is supposed to imply that a practice should be pursued in a particular way. To take that normative step, one needs an argument as to why a practice should be

1 - Thomas Scanlon argues that this is also true of moral principles, in What we Owe to Each Other (Cambridge, MA: Harvard University Press, 1998), $199 \mathrm{ff.}$ 
understood in terms of a particular point that gives it a unified sense as an enterprise - an argument as to why the practice is worth pursuing collectively. ${ }^{2}$ That point will also indicate how the norms of the practice and its proper pursuit should be understood. Saying, for example, that marriage must be defined in terms of intimate commitment requires an argument as to why this is the right point for the practice and why it should be pursued accordingly. There are, then, three levels in discussing the point of a practice:

- The observable facts about how participants actually perform, continue, and understand the practice (and their presuppositions);

- The normative standards that should guide (regulate) how a practice is continued or affected by moral agents (including both participants and non-participants); ${ }^{3}$

- The normative reasons that ought to guide the choice of normative standards for regulating a practice.

When put in this way, we can see that any principles we can attribute to participants, even if they describe or explain the observable facts, are in that sense only candidate normative principles for how the practice should be continued. Yet, the choice of principles by participants will have substantive consequences, in terms of people's rights and duties, for how the practice is continued. Deciding, according to the conservative procreative view of the point of marriage, that only couples of the opposite sex can legitimately marry, will imply that marriage-based claims by same sex couples cannot be considered legitimate. No one will be thought to have a marriage-based obligation to respond to those claims.

Distinctively, practice-dependence accounts constrain the content of normative principles for regulating certain practices by reference to observable facts about those practices. These facts are the role, function, or aim of a practice ("functional role" from now on) for a community of practitioners. ${ }^{4}$ That functional role is derived from a descriptive interpretation of the normbehaviour of the participants. It is a sociological interpretive description. Whilst moral concepts may be used to describe the organising function of the practice, the choice of description is not itself evaluative in the sense of employing moral principles of the kind that are to be applied to regulating the practice. ${ }^{5}$ If the functional role were derived in an evaluative way, for

2 - If there is an "internal point of view" on a practice, then it must refer to this sense. For the notion of an internal perspective, see Scott Schapiro, "What Is the Internal Point of View?", Fordham Law Review, 75 (2006), 1157-1170.

3 - Cf. Andrea Sangiovanni, "Justice and the Priority of Politics to Morality”, Journal of Political Philosophy, 16/2 (2008), 137-164, at 6-7.

4 - Charles Beitz, The Idea of Human Rights (New York: Oxford University Press, 2009), 8 ff.; Andrea Sangiovanni, "Justice and the Priority of Politics to Morality", 18 ff.; Aaron James, "Constructing Justice for Existing Practice: Rawls and the Status Quo", Philosophy \& Public Affairs, 33/3 (2005), 283-284, 300 ff., and Fairness in Practice: A Social Contract for a Global Economy (New York: Oxford University Press, 2012), 30.

5 - Aaron James, Fairness in Practice, 28. 
example as the best role the practice could have given our moral values, the view would not be practice-dependent, but would rather make the point of social practices dependent on these moral values. So, for example the functional role of marriage may differ across different societies and may imply concepts like rights and obligations. It is not, however, derived by considering which notion of marriage best serves values like fairness, equal concern, equal respect, social impartiality, etc., irrespective of the way it is actually understood.

For those theorists, the fact that a practice has a functional role does not entail that the participants believe it plays that function. ${ }^{6}$ They may not have clear views about what they do. It must simply be plausible to interpret and explain the practice norms by attributing that function given the behaviour of participants and its implicit presuppositions. Such interpretations can be better or worse depending on how comprehensively and coherently they account for the norm behaviour. ${ }^{7}$ Nevertheless, the attribution of a functional role is descriptive in the sense that it does not presuppose evaluation. ${ }^{8}$

This functional role, however, will constrain the kind of moral principle that can be appropriately formulated for a practice. For example, principles for politically distributing benefits and burdens between people will only apply to relationships between people in political societies of the kind typified by domestic constitutional states. This is because the shared understanding of the practice of political society is that it functions as a scheme of inter-personal cooperation. The same normative concept does not appropriately apply to a practice with a different functional role, like international trade regulation, which participants take to be about inter-state cooperation.

Sometimes, practice-dependence theorists refer to the functional role of a practice, and sometimes, of a concept within a practice. ${ }^{9}$ However, the idea is essentially the same: the functional role of either the practice as a whole or the part of it that can be referred to in terms of a concept like "international human rights" will shape the kinds of moral principles that should apply to it. Practice-dependence, as I shall understand it then, is the following claim, which I call the aptness claim:

6 - Charles Beitz, The Idea of Human Rights, 107; Andrea Sangiovanni, "Justice and the Priority of Politics to Morality", 10; Aaron James, "Constructing Justice for Existing Practice", 302.

7 - Aaron James identifies the "consistency," "coherence," “comprehensiveness," and being "illuminating" as desiderata for a descriptive interpretation of the functional role of a practice. His stipulation that this interpretation should not be moral-evaluative implies "coherence" is not the same as moral cogency, Aaron James, Fairness in Practice, 29-30.

8 - Aaron James, Fairness in Practice, 28; Beitz, The Idea of Human Rights, 104.

9 - Andrea Sangiovanni shifts from discussing the functional role of practices and institutions ("Justice and the Priority of Politics to Morality", 142,148, 149, 150, and 160) to the function of a concept within a practice (ibid., 148, 151, 152, 153, 155, and 156). Beitz as well refers to the practice of human rights (The Idea of Human Rights, 10-11) and the role of the concept within and the practice (ibid., 12). 
- For at least some practices the formulation and justification of moral principles for their regulation depends on the functional role of the practice in the shared understandings of its participants.

This practice-dependence claim is a claim about the aptness of certain normative principles for regulating a practice, given its functional role. However, different functional roles imply relationships between different groups, such as between members of a political community versus between different political communities. In such cases, practice-dependence entails a scope thesis: that the purpose of the practice, say, to permit inter-citizen cooperation rather than inter-communal cooperation, will define which agents hold moral rights and duties against each other. ${ }^{10}$ Justice in the distribution of personal benefits and burdens will apply between community members in political societies. The practice and institutions underpinning the international society of political communities is not generally understood to have this kind of purpose, so fairness for that practice will be in terms of community advantages and burdens. ${ }^{11}$ Ultimately, scope depends on the functional role of a practice and some practices might not have a functional role that implies such a restricted scope.

The meaning of the aptness claim turns on the word "depends". In these theorists' writings, dependence means that principles of fairness, say, should describe fairness in fulfilling the functional role of the practice in question. That aim constrains what principles can apply. Institutional fairness in distributing benefits and burdens of cooperation between citizens is different from fairness in distributing benefits and burdens of cooperation between states. And whether one or other type of fairness applies is down to what functional role is implied by participants' shared understandings and actions. Contrast this with the view that moral judgement involves pairing principles with relevant facts to arrive at a conclusion. In that case, judgements are modified by facts, including facts about a practice, but not the moral principles themselves. By contrast, the aptness claim entails modifying the principles.

Now, if the aptness claim, and the scope thesis it implies, does not emerge from moral evaluation of a practice, one might ask what rational warrant there is for constraining morality in this way. It cannot be that the functional role of a practice determines the principles that should govern the practice because participants agree with or consent to that being the function. Whilst consent can sometimes legitimate institutions, in those cases it depends on people knowing and believing that they are consenting. The practice-dependence claim, however, appeals to the functional role that can reasonably be interpreted as underpinning the group's behaviour. ${ }^{12}$ Even, however, if consent did

10 - Aaron James, "Constructing Justice for Existing Practice”, 295 and 300, and Fairness in Practice, $30 \mathrm{ff} . ;$ Public Affairs, 35/1 (2007), 3-39.

11 - E.g. Aaron James, Fairness in Practice, 30.

12 - Charles Beitz, The Idea of Human Rights, 107-108; Aaron James, "Constructing Justice for Existing Practice", 303-304; Andrea Sangiovanni, "Justice and the Priority of Politics to Morality", 13. 
lie behind the view, it would then be an example of a moral-evaluative view: agreement-dependence, rather than practice-dependence. The force of that view does not come from the functional role of a practice, but from the moralevaluative power of agreement.

\section{Who's for practice-dependence?}

The aptness claim is at the heart of the practice-dependence approach, as I have described it, and this has consequences for the scope of moral principles, such as the principles of justice and human rights. In this section, I show that three authors, namely Charles Beitz, Andrea Sangiovanni, and Aaron James, adopt the aptness claim and explain how that shapes their views on the scope of different moral principles.

Beitz proposes a practice-based approach to developing an account of human rights. Due to the role that Beitz takes the concept of human rights to play in international practice, human rights standards are appropriately applied to certain kinds of relationship only. His chief conclusion is that an account of human rights that is faithful to the functional role of human rights will be one where the concept is used primarily to judge the international legitimacy of states in terms of how they treat their citizens. ${ }^{13}$ Beitz explains the concept of human rights, including the type of social relationships to which it applies, by reference to "the role this concept plays within the practice". ${ }^{14}$ Andrea Sangiovanni does the same. ${ }^{15}$

This functional role is gleaned from "what an ordinary competent participant in the discourse of human rights would understand". ${ }^{16}$ So, like practicedependence accounts of justice, he appeals to a sociological description of function to explain features, such as appropriate application, of a moral concept. These include the acceptance by "ordinary competent participants" in the international practice that human rights are about the tri-partite relationship of citizens, their treatment by their states, and third party state action when that treatment is sufficiently bad.

For Sangiovanni as well, "[t]he content, scope, and justification of a conception of justice depends on the structure and form of the practices that the conception is intended to govern". ${ }^{17}$ It is clear that the intention is that the formulation and justification of moral principles should be constrained according to people's shared understandings of the functional role of the

\footnotetext{
13 - Charles Beitz disparages other views as "question-begging in presuming to understand and criticize an existing normative practice on the basis of [a governing conception that] does not, itself, take account of the functions that the idea of a human right is meant to play, and actually does play, in that practice". Charles Beitz, The Idea of Human Rights, 8.

14 - Charles Beitz, The Idea of Human Rights, 8.

15 - Andrea Sangiovanni, "Justice and the Priority of Politics to Morality", $16 \mathrm{ff}$

16 - Ibid., 11

17 - Ibid., 2.
} 
practice: "existing institutions and practices should play a crucial role in the justification of a conception of justice". ${ }^{18}$

James holds that the nature of the principles of justice that apply to an institutional order must be constrained by the functional role of the practice to which those institutions belong. ${ }^{19} \mathrm{He}$ attributes this view to Rawls, and I will question whether this is indeed Rawls' view below. That aside, the view takes facts about a practice as the basis, when suitably interpreted, for discerning its functional role: "a proposed characterization of the nature and purposes of a practice cannot be a mere worthy moral ideal; it must also be in some sense generally accepted among participants". ${ }^{20}$ The reference to not being a "mere [...] moral ideal", but also one that is accepted, seems to imply that of all the generally accepted functional roles, the ones being considered must also be morally justified. I shall return to this question shortly. For now, it is important to note that the view cannot be that social aims need to be underwritten by justice, in addition to being accepted, in order to define the functional role of a practice. Otherwise the view would be somewhat circular, with principles of justice telling us which functional roles are valid, and valid functional roles then contributing to defining the principles of justice appropriate to judging them.

For James, the functional role of a practice or, in his terminology, its "aim", determines its aptness for judgments of social distributive justice. If the aim of the practice of political society is to be "a cooperative venture for mutual or reciprocal advantage", then an account of justice as a moral concept applicable to that practice should reflect this aim. ${ }^{21}$ That account of justice will differ from an account of justice for institutions with a different aim, such as those for international trade, given " $\mathrm{t}]$ he aim of international law and practice is to create goods of peace, national autonomy, and to uphold basic domestic justice, and to do so in a way that reflects mutual societal recognition". 22

The functional role of a practice is contingent and historically specific. Beitz explicitly refers to this role as a historical sociological description, contrasting it with a normative description. ${ }^{23}$ Sangiovanni takes the relevant functional role to be the one "intended" for justice, or for human rights. ${ }^{24}$ It is shaped by "contingent historical and political contexts constituted by [...]

18 - Ibid., 1. My emphasis.

19 - Aaron James, "Constructing Justice for Existing Practice”, 295, 300. Note, at 302, his characterization of Rawls' project as one of social interpretation: "If nothing but bold moral assertion could justify Rawls's favoured characterizations, we cannot charitably view him as fundamentally engaged social interpretation after all."

20 - Ibid., 301.

21 - Ibid., 300 and Fairness in Practice, 26.

22 - Ibid.

23 - Charles Beitz, The Idea of Human Rights, 8 and 12.

24 - Sangiovanni, "Justice and the Priority of Politics to Morality", 148, 150, 151. 
institutions". ${ }^{25}$ This is due to its basis in practice norms that are responsive to the "shared understandings" of participants. ${ }^{26}$ Hence the interpretative question being "most importantly, what role is justice meant to play among participants?" ${ }^{27}$ Similarly, for James, it is the "accepted role" of the practice that represents its functional role in his method. ${ }^{28}$

All three theorists accept that descriptive interpretation is needed in order to establish the functional role of a practice. For Sangiovanni, whilst some interpretation takes place, it is primarily descriptive, so that any "assessment of merit is a general and provisional one, aimed at seeking understanding of what in the institutional system might motivate the affirmation of its participants, rather than a judgment about whether it is, all-things-considered, just or unjust". ${ }^{29}$ This is an explicit response to the possibility that our interpretation of a practice might apply values we, rather than the participants, endorse. That is treated as something we should aim to avoid to the degree that we can. ${ }^{30}$ Beitz too stipulates that, unlike Dworkin's interpretivism, he derives the functional role of human rights from the actual norms of the practice, not from a moral ideal. ${ }^{31} \mathrm{He}$ is committed to a form of social interpretation that does not require value judgements to underwrite its cogency. ${ }^{32}$ James' stipulation that the descriptive interpretation of the functional role of a practice must be something that an "amoralist anthropologist" could arrive at confirms that the idea is not evaluative. ${ }^{33}$

Both James and Sangiovanni explicitly claim inspiration from Dworkin's interpretive method for the steps necessary in arriving at a functional role. ${ }^{34}$ However, they reject the moralised version of interpretation offered by Dworkin. James approvingly takes Rawls to differ from Dworkin on this point, namely that interpretation requires strong evaluation. ${ }^{35}$ Dworkin, as we shall see below, does not formulate principles of justice by reference to the institutions of any particular society. Rather, he derives them from reflection on our elemental moral convictions. In that method, any conviction or shared

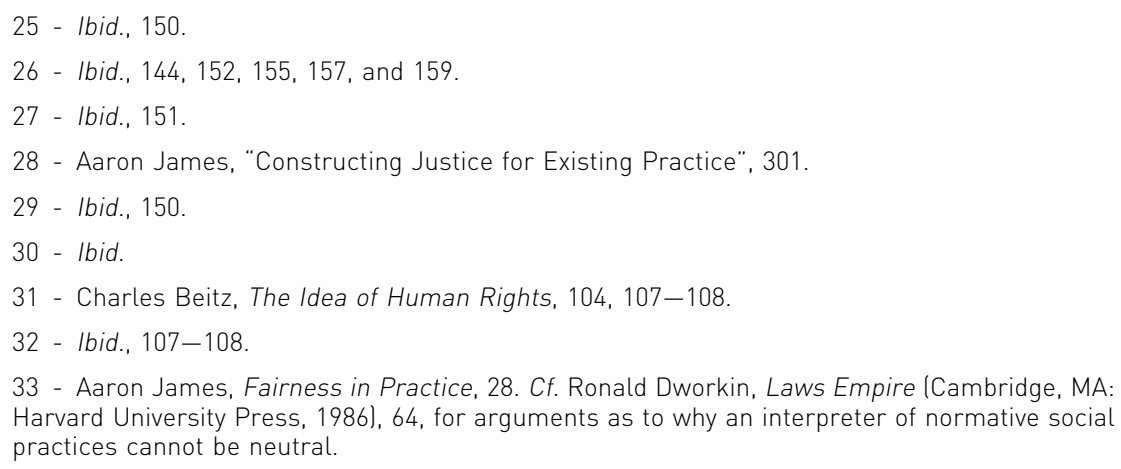
Harvard University Press, 1986), 64, for arguments as to why an interpreter of normative social practices cannot be neutral.

34 - Aaron James, Fairness in Practice, 27, n. 46; Andrea Sangiovanni, "Justice and the Priority of Politics to Morality", 148, n. 27 and ff.

35 - Aaron James, “Constructing Justice for Existing Practice”, 301, n. 39. Some "thin" evaluation is permitted to get a functional role into shape. See Aaron James, Fairness in Practice, $28-29$. 
understanding about a practice is a starting point that can, however, be ultimately revised for the sake of moral cogency. This feature challenges the aptness claim, which constrains moral principles according to shared understandings of a practice's functional role, and for that reason James rejects it as too "protestant" an approach to interpretation. ${ }^{36}$ It is also in conflict with Sangiovanni's view that the "interpretive stage is to establish the parameters and fixed points" constraining our formulation of principles for the practice. ${ }^{37}$

Along with the aptness claim, these views have scope implications. Beitz's practice-based account of the role of human rights limits the appropriate scope of human rights judgements to a tri-partite relationship. An issue will not be a human rights question unless there are state-person relationships in play, and treatment in those relations is sufficiently serious to form the reasonable basis for a third party international response. ${ }^{38}$ So, on this view, facts about an international practice explain the nature of substantive principles that should guide the continuation of that practice. ${ }^{39}$

James and Sangiovanni too see the scope thesis as following from a proper appreciation of the function of the practice of political society, and the role of the concept of justice in relation to that function. The aim of international institutions, as they "see themselves" and their participants see them, does not include establishing reciprocity or cooperation between persons for mutual or reciprocal advantage. ${ }^{40}$ Domestic political society, practiced in a certain way, is plausibly understood as encompassing those aims, and so participants in political societies of this kind are in relations that are (distributive) justice apt. ${ }^{41}$ The same relationship does not exist between people in different societies, who do not share certain types of societal institutional practice. For them, justice as inter-citizen fairness is not appropriate to judging relationships between civic strangers. One cannot make distributive fairness claims against the other's society. However, other concepts of justice, such as justice between states, may apply, depending on the aims of the inter-state practice.

This now brings me to an important ambiguity alluded to above. At least in James and Sangiovanni, sometimes the functional role of a practice is a matter of descriptive interpretation; and sometimes it has to be cast as being a "morally legitimate purpose". ${ }^{42}$ Sometimes it is contingent and sociological; sometimes it must be "publicly acceptable to all citizens of a democratic

36 - Aaron James, Fairness in Practice, 27, n. 46.

37 - Andrea Sangiovanni, "Justice and the Priority of Politics to Morality", 149.

38 - Charles Beitz, The Idea of Human Rights, 106.

39 - Ibid., 11 and 105.

40 - Andrea Sangiovanni, "Justice and the Priority of Politics to Morality", 151-153 and 159; Aaron James, "Constructing Justice for Existing Practice", 300.

41 - Aaron James, "Constructing Justice for Existing Practice”, 295.

42 - Aaron James, Fairness in Practice, 29, 30. 
society". ${ }^{43}$ Sometimes we see it as the functional role that is actually implied by people's practice; sometimes as a rational consideration in framing a theory of justice. It seems that functional roles have a dual character. Given that these theorists want an account of justice to be warranted by rational argument, functional roles must play a normative role in developing that account; they must be in some sense positive moral considerations. Yet, they are derived from descriptions of facts, albeit charitably interpreted to render them consistent and coherent. Even the reasons in favour of a particular functional role, discerned through interpretation, are "reasons from the point of view of the participants". ${ }^{44}$ The only way in which functional roles could be normative considerations is if there are reasons for promoting them from descriptions of reasons to actual reasons in our deliberations about justice. Such promotion already implies an independent moral justification, such as the importance of the practice for people's pursuit of a conception of the good, or the consent of participants.

It is telling that James' examples of considerations emerging from the functional roles of practices are all considerations perfectly explicable in terms of pre-established moral principles. These include "morally relevant interests" and claims of participants in a given context, the agents involved and their powers, and considerations about epistemic uncertainty with regard to regulative courses of action. ${ }^{45}$ Again, one could interpret a "morally relevant" consideration here as any considerations that is morally relevant, explicitly or implicitly, for the participants in a practice. But to be normative considerations for an account of justice, moral principles must tell us which interests are genuinely morally relevant and why. After all, there are many things people or even groups can treat as interests of fundamental moral relevance, such as access to the afterlife or purity of race, which are not relevant to judgements of justice. Moral principles are needed to explain why justice should or should not be formulated in terms of these interests and corresponding agents, not any fact about the practice. ${ }^{46}$ But accepting this would make the view a moral principle-dependent view, not a practice-dependent one - as it only makes judgements practicedependent, not principles. So, to preserve the aptness claim in what follows, I will interpret the "morally relevant" considerations to be simply those assumed as relevant for the practice in the shared understandings of practitioners.

Some of the literature has been somewhat imprecise as to what counts as practice-dependence. This is because the aptness claim has not been properly

43 - Andrea Sangiovanni, “Justice and the Priority of Politics to Morality", 151.

44 - Ibid., 148, 149, 150.

45 - Aaron James, Fairness in Practice, 26, 28, 29, 114, 115. I note that these very same morally relevant features are raised as part of a non-practice-dependent account justifying scope restrictions on justice. See Saladin Meckled-Garcia, "On the Very Idea of Cosmopolitan Justice: Constructivism and International Agency", Journal of Political Philosophy, 16/3 (2008), 245-271.

46 - The former might be explanatory or methodological principles, in Cohen's sense (G.A. Cohen, "Facts and Principles", Philosophy \& Public Affairs, 31/3 (2003), 211-245, at 219 and 220), but that does not change the fact that they are not practice-dependent. 
isolated as distinctive of the view. As a result, views that merely take some features of practices to be relevant for moral judgement, even in addition to independently derived moral principles, have been classified as practicedependent. One author identifies views as "functionalist" practice-dependence accounts merely because they make reference to morally relevant features of practices, based on independent moral principles, without an aptness claim. ${ }^{47}$ On that view, a plausible moral principle will imply "triggering conditions" morally derivable from the moral point of the principle, or the moral value it serves. Those conditions indicate when the principle is applicable to the facts, including facts encompassing practices. Principles to avoid harm are triggered in conditions where there are moral agents capable of harm, for example. Sometimes the triggering conditions will be facts about social practices and their capacity to affect people. There is, however, nothing distinctively practice-dependent in that claim, given that the formulation of a moral principle is not constrained by those facts, and given that facts about practices are not the only facts that can contribute to moral judgement. I shall proceed, then, on the assumption that views are genuinely (and, as we have seen, explicitly) practice-dependent where they hold an aptness claim. For such views, there is an important moral objection that I will now set out.

\section{The justifiability objection}

There is something morally problematic in allowing the contingencies of the functional role of a practice or concept to have substantive consequences in terms of people's rights and duties. The aptness thesis does exactly that. Whilst I would beg the question against the view by criticising this as an injustice, as that is the concept in contention, there is a more neutral moral ground from which to mount the objection. It is the notion of justifiability. Any modification, on whatever basis, of people's moral rights and duties has to be justifiable to those who will carry these rights and duties.

Restricting the scope of a principle because the functional role of a practice implies restricted scope would only be acceptable if that restriction were justifiable to those who will be affected. The kind of reason that might be given to a person for taking from, or adding to, her moral rights and duties, however, can only be a substantive, value-based reason. And because we are considering what obligations people might be required to shoulder, even where they may not consent to those obligations, this has to be a value-based moral reason. Liberal moral theories place peremptory value on people being able to pursue

47 - Laura Valentini, "Global justice and Practice-Dependence: Conventionalism, Institutionalism, Functionalism", Journal of Political Philosophy, 19/4 (2011), 399-418, at 414. See also Miriam Ronzoni, "The Global Order: A Case of Background Injustice? A Practice-Dependent Account", Philosophy \& Public Affairs, 37/3 (2009), 229-256, whose criterion for being a practice-dependent account is "that the appropriate principles of justice for specific practices depend on the nature of those very practices" (op. cit., 231). This criterion is ambiguous between an aptness claim and views with independently derived principles that are triggered by certain morally relevant conditions. 
conceptions of the good life that they have selected themselves. On this, the practice-dependence theorists do not dissent. If that is indeed a moral value that is worth preserving, then any restriction or any imposition of duties that curtails people's adoption or pursuit of their conception of the good needs to be justified. Justification is especially needed for those who will bear the burden of having their choices curtailed. Yet, the only reasons of sufficient status to outweigh a moral value of this kind are reasons based on the same, or another moral value - only they can show why curtailing choice in this way matters enough to make it obligatory.

We accept that people's freedom to pursue their own conceptions of the good life does not entitle them to harm others. This restriction is itself based either on the moral value of the freedom to adopt and pursue one's own life aims, which is undermined by harms, or in the inherent moral value of avoiding harm. Either way, it takes a consideration based on moral value to justify the restriction of people's pursuit of their life aims.

What I am proposing, then, is that the only morally sound justification for adopting or constraining the application of a substantive principle, as a moral principle, is one that refers to a moral value. Substantive moral principles are those that directly assign moral entitlements and obligations. ${ }^{48}$ This justifiability constraint on accounts of moral principles can be formulated as follows:

- Any argument supporting a substantive moral standard for a given group of people must be justifiable by reference to at least one moral value or independently derived moral principle.

The aptness claim affects substantive moral principles. Beitz, for example, identifies the functional role of human rights as standards that, when breached, can justifiably trigger international concern and action. ${ }^{49}$ That is at least partly based on an assessment of the role of the concept of human rights in international human rights practice. ${ }^{50}$ It means, though, that some claims will not count as human rights because, for example, they will not be suited to international action. ${ }^{51}$ Sangiovanni's and James' claim that the role of justice differs in domestic practices from that in international institutional practices means that we do not have the same, justice-based rights against the rest of the world as we have against compatriots. ${ }^{52}$ So these are substantive moral conclusions, yet based on methodological considerations about the functional role of a practice.

48 - Some morally relevant methodological principles, such as "do not adopt contradictory principles", do not require value-based justification. Because their basis is simply an extension of constraints on reasoning as such, they are not especially moral or substantive principles.

49 - Charles Beitz, The Idea of Human Rights, 44. 137.

50 - Ibid., 129.

51 - Ibid., 106, $140 \mathrm{ff}$.

52 - Aaron James, “Constructing Justice for Existing Practice”, 308 ff., Sangiovanni, “Justice and the Priority of Politics to Morality", 152. 
For these views to pass the justifiability test, they must be consistent with the justifiability constraint. This means that constraining the application of moral principles in the relevant way is justifiable by reference to some moral value. We need a reason as to why it matters, morally, that principles are constrained in this way. As I have said above, there are good reasons to think that this is not a consent-based argument, but if it were, then the value would be something akin to the individual liberty to purse a conception of the good. So what is the value that underpins the aptness claim? The mere fact that people, individually or collectively, behave in a certain way is not by itself valuable, given that some practices, such as apartheid, can have rotten functional roles. Either practice-dependence theory must show that some moral value is served by constraining principles according to a functional role, or it must provide a cogent challenge to the justifiability constraint. I will here consider some possible responses from the practice-dependence approach employing each of these strategies.

\section{a) Specific application of higher-level principles}

One response to the justifiability objection is to argue that the moral principles applying to a practice, at an abstract level, are indeed morally justified without reference to the practice. It is just that when it comes to figuring out how they apply to a specific practice concretely, we need to look at the point of that practice. ${ }^{53}$ The point of the practice, as understood by its participants, conditions the application of the abstract moral principles because, apparently, "sharing [a context] shapes the reasons we might have for endorsing specific principles of justice". ${ }^{54}$ However, no indication is given as to what this "shaping" of reasons might mean.

If a moral principle, say, a principle of equal concern or equal respect, however abstract, genuinely applies to relations in a particular context, it is because some feature of those relations triggers the conditions for applying the principle. The principle, or at least its rationale, will specify for example what kinds of interests have to be affected in order for principles of equal concern and equal respect to be triggered. If the rationale is the moral value of people reasonably pursuing their chosen conception of the good, then the relevant interests that will trigger the principle will include the freedoms and resources that connect with this value. It will not include the interests that some people might have in, say, unfairly inhibiting others. But the reason for specifying the application conditions of a principle in that way - what I have called its "triggering conditions" - lies in the moral rationale of the principle. No reason of that kind will emerge from practice-based considerations. In fact, if practices do specify the way in which an abstract principle is applied, it is only to the extent allowed by the principle and its rationale. Practices may add detail, colour, specifics, but these are detail, colour and specifics in how an

53 - Andrea Sangiovanni, "Justice and the Priority of Politics to Morality", 147.

54 - Ibid. 
independently derived principle applies, given that it already applies. They are not independent considerations as to whether the principle should apply or not. That matter is already decided by the point of the principle, not the point of the practice to which it applies.

The "shaping" metaphor is out of place here. The appropriate description for the relationship between abstract principles and more specific principles is, in fact, either specification or abstraction. More abstract moral principles group together, by abstraction, more specific principles that have the same moral point in common. On one theory, contracts, international treaties, and promises to meet at the cinema, are all specific forms of promising, falling under a general principle that one should do what one formally undertakes to do. A challenge to this theory would be that, for some types of undertaking, the basis is another moral value, or includes another moral value that makes a difference to how we judge specific cases. We might, for example, say that the fact that one cannot promise on behalf of another, but one should be able, as a government representative, to ratify an international treaty on behalf of a population, demonstrates that different values explain the principles in each case. Principles for keeping promises are explained by the value of interpersonal cooperation that respects individual autonomy, whilst principles for adhering to treaties are explained by the value of inter-communal cooperation that respects collective self-determination. Where two principles are more specific examples of the same abstract principle, they will share the moral rationale of that principle. On some views, contracts and promises are more specific versions of the same principle; the rationale is the same. ${ }^{55}$ And it is the rationale that justifies and explains the scope of a principle, not any particular features of a specification that are peripheral to the rationale. Fairness between citizens and fairness between political communities are not specifications of the same principle if a different rationale is present in trying to formulate each idea. Whether they are specifications of the same principle or not is not a matter of the function of a practice, but a matter of whether a different moral value is served in each case.

So, any insistence on the aptness claim is still in need of an account as to its consistency with the justifiability constraint, or with moral reasoning generally. The notions of abstraction or specification and their roles in debates on the scope of justice owe nothing to practice-dependence.

\section{b) Interpreting the practice discloses valuable information}

Another argument in favour of treating the functional role of a practice as a consideration is that this may disclose important insights. There may be questions of value, or relationship interactions, that a priori moral reasoning would not disclose. Reflecting on " $\mathrm{t}]$ he history of institutions is important [...], because it records the results of cooperation in conditions of fundamental 
political conflict and disagreement". ${ }^{56}$ So, for example, we are told that the first aim of social institutions, and so their primary role is "to secure conditions of order, trust, cooperation, and security among human beings. Political authority is necessary because without it, distrust, insecurity, and the desire for recognition [...] will thwart any possibility of cooperation or render it incredibly fragile". ${ }^{57}$ That, presumably, is an aim we would overlook if we did not pay attention to the practice, and the role of institutions within it. From the high "perch" of abstraction, those who do not subscribe to practice-dependence will remain "blind to the underlying and sustaining structures that make the pursuit of justice both possible and necessary". ${ }^{58}$

It may be true that sensitivity to key social factors, such as distrust, insecurity, and desire, and how they manifest themselves, will make for a better moral theory, but there is no practice-dependence moral to this story. The legitimacy and stability of states are values that plausibly demand moral principles of their own. Indeed there is a rich literature distinguishing the basis for political legitimacy and authority from accounts of social (distributive) justice. ${ }^{59}$ The presence of institutions that satisfy the former standard is a necessary, but not a sufficient condition for those institutions satisfying the latter. Neither of them needs to appeal to the functional role of a practice for the community of participants. Political legitimacy and justified authority, too, need a moral value basis, consistent with the justifiability constraint precisely because those relationships are challenging to a moral perspective that values individuals reasonably pursuing their conceptions of the good. They are not exempt from the justifiability requirement merely because they seem to be a presupposition in the practices of modern states. So, whilst history and sensitivity to practices may help us see concerns that we might otherwise miss, that they are concerns is a matter of moral value, not of their part in the functional role of a practice.

\section{c) Conceptual versus substantive role}

One way to make a case for the aptness claim is by appeal to a non-moral notion of normativity. Instead of trying to show that practice-dependence is compatible with the justifiability constraint, one can reject the constraint. This is done by giving reasons for taking a practice-derived role or function of a concept as a different kind of non-substantive reason for understanding that concept in a certain way. Beitz, for example, appeals to our practices as a way of understanding the concept of human rights that is not based on a substantive view about human rights. It is based, rather, on how we understand a concept as the background for disputes between substantive accounts. The concept

\footnotetext{
56 - Andrea Sangiovanni, "Justice and the Priority of Politics to Morality", 156.

57 - Ibid., 157.

58 - Ibid.

59 - It is unclear whether Sangiovanni distinguishes these as separate questions in "Global Justice, Reciprocity, and the State", $13 \mathrm{ff}$.
} 
frames disagreement, rather than taking a substantive position in the debate. ${ }^{60}$ So, we "rely on the practice for an understanding of the discursive roles of human rights, not (or anyway not directly) to delineate their scope or content". ${ }^{61}$ This way of approaching the concept "claims for the practice a certain authority in guiding our thinking about the nature of human rights". ${ }^{62}$ But what is the basis for this authority? Beitz does not supply an argument, except that we can make sense of the two different questions of when we are asking about the concept, and when we are asking about substantive views as to the content of the rights. ${ }^{63}$ The concept is already in use, and people make decisions that involve use of the concept. ${ }^{64}$ In one passage, he cites Searle's view of social construction. ${ }^{65}$ Searle himself appeals to "collective intentionality" imposing meaning on collections of objects to create social-institutional facts. ${ }^{66}$ Perhaps the best way to understand this point is as the conceptual thesis that whatever the practice that a community collectively understands by human rights happens to be just is what, as a concept, human rights are. This can be kept apart from the question of what they entail substantively. So there are two theses here: the conceptual dependence thesis and the substantive separateness thesis.

I will not try to deal with the conceptual dependence thesis here, although it seems just as plausible that how concepts should be understood is sensitive to reason (their relations to other concepts) rather than group agreement. That rights are not duties is sensitive to reasons about what of importance is captured in rights talk that is not captured in duty talk alone. Even if the whole community thought that justice is the same as promising, there are good reasons to think that it is not. But, that aside, the key question for a practicedependence approach like Beitz's is whether the conceptual question can be kept separate from the substantive question.

If we recall, the objection to practice-dependence is that it sources reasons to treat justice as having a certain scope in considerations of the function of the concept within a practice (the aptness thesis). Without adding an additional premise appealing to a moral value or a moral principle independently derived, the aptness thesis seems incompatible with the justifiability constraint: the idea that substantive consequences need to be justified by reference to moral values or principles. Claiming that a conceptual account of a moral notion, based on the role of a concept in a practice, can be arrived at without substantive commitments still falls foul this constraint. That is because conceptual views about human rights cannot avoid having substantive consequences. Beitz admits that

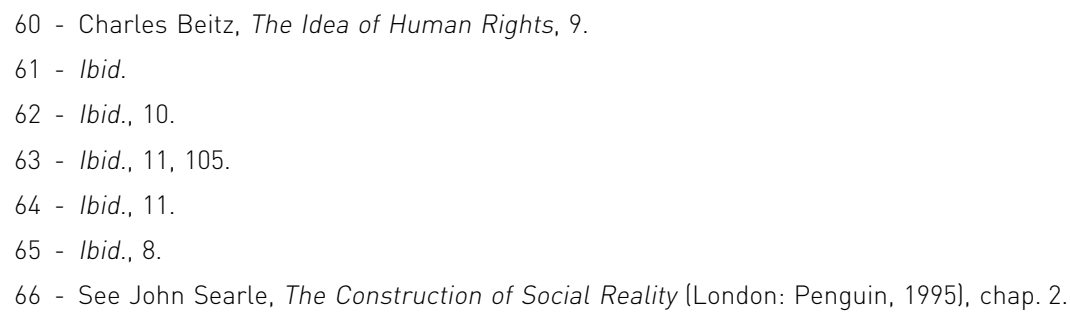


much, as is revealed by the "or anyway, not directly" parenthetical comment in the above quote, and his admission that the questions are related. ${ }^{67}$ Indeed, the only way an account of a moral notion could be conceptual and not substantive would be by being purely a view about categorisation: what we call some moral duties and rights versus others. Adopting it would not alter what rights and duties we believe to be justified. Such a concept would not be much of a contribution to normative theory, given that it would only ask us to name things in a certain way. The point of views such as Beitz's, Sangiovanni's, and James', is to say something about the substantive entitlements and obligations people have, such as their scope. In so far as their views are meant to serve that purpose, and in so far as they do not provide substantive, value-based arguments for the aptness claims in each case, they breach the justifiability constraint. They are views without a rational grounding for their central thesis.

\section{The misappropriation of Dworkin and Rawls}

Both practice-dependence theorists and their critics have taken Dworkin's interpretivism to inspire practice-dependence methodology. ${ }^{68}$ In particular, they take his notion of "fit" to imply an aptness claim. ${ }^{69}$ Dworkin's theory of interpretation takes it that the correct way to interpret any rational human practice is by finding principles that will show this practice in its best light. If a practice deals with morally important goods and burdens, then the relevant principles will have to be moral principles that can justify assigning these goods and burdens one way rather than another. ${ }^{70} \mathrm{We}$ are invited to see if any moral principle will "fit" with the possible aims or point of the practice. If we find principles that do, then these are said to be suited to showing the practice in its best light, and they are the rationally appropriate principles for guiding decisions about how the practice should be continued into the future. So if the moral principle of equal concern is appropriate for guiding coercive practices, we can say that decisions about how the practice will be continued must refer to the principle of equal concern and what distribution of coercion in a community best expresses that value. This resembles the interpretive approach that at least James and Sangiovanni propose for determining the function of a practice or the role of justice for that practice. That is, however, a misappropriation.

67 - Charles Beitz, The Idea of Human Rights, 11.

68 - Andrea Sangiovanni, “Global Justice, Reciprocity, and the State”,148. Beitz explicitly rejects Dworkin's approach to interpretation (The Idea of Human Rights, 107 and 108), whilst James claims to use Dworkin's interpretive steps without adhering to his more "protestant" view of interpretation (Fairness in Practice, 27, n. 46).

69 - Ronald Dworkin, Laws Empire, 67; Aaron James, "Constructing Justice for Existing Practice", 301; Valentini, "Global Justice and Practice-Dependence", 404.

70 - Dworkin's key examples of morally important goods and burdens are those created by the deployment of coercion in a political community. Justice, or equal concern, is the right principle for deciding how coercion can be legitimately deployed. See Ronald Dworkin, Laws Empire, $190 \mathrm{ff}$. 
As James recognises, Dworkin's approach to developing or justifying moral principles makes no reference to practices, but in fact refers to any rational deliberator's "abstract elemental convictions". ${ }^{71}$ It means that Dworkin's moral methodology is based on appealing to values to explain core intuitions, or paradigm examples. No moral normative force is attributed to practices. ${ }^{72}$ In that, he shares something in common with most moral philosophy, which proceeds by reasoning from intuitions or core convictions. The notion of fit, which is one source of misunderstanding of Dworkin's work, plays no normative role in this process. Rather, fit must be understood conditionally. Practices are worth continuing to the degree that a certain reading of them (how to continue them) shows them in their best light. Best light here makes reference to fulfilling moral values that are independently justified. ${ }^{73}$ Fit only makes a difference to the question of whether we are interpreting an existing practice or inventing something new by bringing moral values to bear on decisions about the practice. ${ }^{74}$ Nowhere in Dworkin is there an obligation not to invent something new, or to be bound only to existing social practices, when developing moral principles. In fact, the interpretation of social practices requires that we have independently arrived at moral values that we can bring to bear on them. ${ }^{75}$ So both the practice-dependence theorists and their critics, who take Dworkin to inspire the shaping of moral principles, or the restriction of their application, according to the aims of a practice, misunderstand his account of interpretation. Take one critique of Dworkin's view as a practicedependence account that takes Dworkin to hold that principles of justice "must reasonably fit with a descriptive account of such practices". ${ }^{76}$ As scholars of Dworkin have been at pains to point out, that is not Dworkin's view and certainly not a consequence of his methodology. ${ }^{77}$

A great deal of mischief in understanding Dworkin's theory of interpretation has been done by running together this notion of fit, with his account of integrity in law. Integrity is the value of allowing legal decisions to be shaped by legal history in a community. The latter is not justified as a moral methodology, but as a substantive expression of equal concern. It is one of the moral values that may, or may not fit a practice, to show it in its best light. In this case the practice is legal reasoning. The cogency of integrity as an idea that shines a good light on the practice of law derives from its justification as a moral value. ${ }^{78}$

\footnotetext{
71 - Ibid., 435, n. 20.

72 - Ibid.

73 - Ronald Dworkin, Laws Empire, 54, 66 ff., 72; Justice in Robes (Cambridge, MA: Harvard University Press, 2006), 145-162; Justice for Hedgehogs (Cambridge, MA: Harvard University Press, 2011), $166 \mathrm{ff}$.

74 - Dworkin, Laws Empire, 67-68.

75 - Ibid.

76 - Laura Valentini, "Global Justice and Practice-Dependence”, 407.

77 - Stephen Guest, "How to Criticize Ronald Dworkin's Theory of Law”, Analysis, 69/2 (2009), 352-364, at 354 and 356.

78 - Ronald Dworkin, Laws Empire, $176 \mathrm{ff}$.
} 
For Dworkin, a practice is a starting point for inquiry. But it neither defines nor constrains the moral arguments for principles of justice, only perhaps for which moral principles can vindicate a particular practice rather than start something new altogether. Justice requires that equal concern and respect be shown by coercive institutions of a political community to its members. That restriction is based on the idea that wielding coercive power is a morally salient feature of a political community. This power must, then, only be used in a way that is morally justified and justifiable. ${ }^{79}$ That focus on coercion, and its associated restriction on the scope of justice is not based on how participants view the practice. It is based on a vindication of the practice from the point of view of morality. So, the phrase "point and purpose" in Dworkin does not apply to the practice and participants' understanding of it, but to the moral concepts that can be used to make best sense of it, and guide its justified continuation, where sense can indeed be made of it. ${ }^{80}$ Morality is the source from which a rational point is attributed to the practice, if a morally sound point can be found, not the other way round. ${ }^{81}$ In the end, Dworkin's method is therefore the opposite of practice-dependence, and it is incompatible with the aptness thesis. It is the view that practices must depend on moral interpretation if they are to be continued in a justifiable way.

Rawls too has, in my view, been mistakenly enlisted for the practice-dependence cause. James takes him to "reason from" descriptions of actual existing practices, but what "reasoning from" might mean here is unclear ${ }^{82}$. Rawls himself certainly does not describe a process where he attributes an aim or function to any practice. In fact, the idea of interpreting a practice by attributing a function to it does not feature in Rawls' method at all. He uses the notion of a role for institutions and conceptions of the person and of society. ${ }^{83}$ However, the notion of a role in these cases is that of playing a role within a coherent overall theory of how the elements of a political order should fit together. It is a normative notion of role, not a descriptive interpretive one. These conceptions and their role within the theory can be reinterpreted for

79 - Note that some well-known applications of scope restrictions to justice in the global justice debate appeal to exactly this kind of (practice-independent) argument. See, for example, Thomas Nagel, "The Problem of Global Justice", Philosophy \& Public Affairs, 33/2 (2005), 113-147. In spite of this, his view is characterised as practice-dependent by Andrea Sangiovanni, "Justice and the Priority of Politics to Morality", 138.

80 - And it is accepted that sometimes it cannot be justified under any plausible moral reading: there is no continuation of the practice that is acceptable. See Ronald Dworkin, Laws Empire, $101-102$.

81 - So Valentini's complaint that Dworkin "paradoxically" deviates from his own practicedependent methodology when considering higher level moral values (Laura Valentini, "Global Justice and Practice-Dependence", 408) is based on an important misunderstanding of his project and method. In fact she seems to run together Dworkin's approach with Michael Walzer's, Icf. 407, n. 29), given that these are the only two theorists she discusses as holding the "conventionalist" version of practice-dependence.

82 - Aaron James claims that John Rawls "has reasoned from [existing practices] all along" ("Constructing Justice for Existing Practice", 284).

83 - John Rawls, Political Liberalism (New York: Columbia University Press, 1993), 107 ff. 
the sake of coherence, rather than being fixed points that condition his account of justice:

The exposition of justice as fairness starts with these familiar ideas [from a democratic public political culture]. In this way we connect it with the common sense of everyday life. But because the exposition begins with these ideas does not mean that the argument for justice as fairness simply assumes them as a basis. Everything depends on how the exposition works out as a whole and whether the ideas and principles of this conception of justice, as well as its conclusions, prove acceptable on due reflection... ${ }^{84}$

As we see, Rawls does indeed appeal to the commitments of a particular culture, but as the starting point from which he works up his conception of justice. Whether any aspect of a political culture gets incorporated into the final theory, and how it gets incorporated, is not settled. It is a matter of "due reflection". In fact, the ideas that Rawls takes from political culture play the role that intuitions or considered convictions play in moral reasoning, or that our convictions about "paradigm" examples play in Dworkin's moral theory. ${ }^{85}$ We take these convictions and see if we can integrate them into a coherent whole according to value-based reasons. No conviction is secure against revision in this approach.

There is, then, a great deal of distance between Rawls' approach to moral political theory and practice-dependence. Unsurprisingly, this shows up as strain in attempting to fit Rawls into the practice-dependence frame. James, for example, comments that Rawls never engages in the "dirty work of interpretive argument". ${ }^{86}$ James also tries to explain away Rawls' insistence that his is an enterprise in practical reason, and that the ideas whose role he considers are ideas in "practical reason". ${ }^{87}$ But in fact Rawls never refers to the function or aim of a practice. He never engages in interpretive reasoning, and he insists that the ideas he works up into his coherent theory of justice can be incorporated or revised by due reflection and practical reason. That means by substantive reasoning on the merits of an account of justice that incorporates them. Unlike practice-dependence accounts, this sounds like the unremarkable practice, in moral theory, of seeking a coherent moral view by using intuitions and ideas from our political culture as a launch point.

Both Rawls and Dworkin can be described as engaged in a vindication test. The first tests ideas from our political culture to see if they can be made into a coherent account. The second tests social practices to see if they can be saved for morality by appeal to an independently derived moral principle that can

84 - John Rawls, Justice as Fairness. A Restatement (Cambridge, MA: Harvard University Press, 2001), 5. My emphasis.

85 - Ronald Dworkin, Laws Empire, 72; Justice in Robes, 218-219; Justice for Hedgehogs, $160-170$.

86 - Aaron James, "Constructing Justice for Existing Practice", 304.

87 - Ibid., 300, n. 37. 
show them under a good moral light. The latter view prescribes that agents of vindicated practices should continue those practices, shaping their future, in terms of the vindicating moral principle. Rawls is, however, willing to change the understanding of concept roles from the practice for the sake of moral coherence. The moral principles, in the first view, come from practical reason, coherence, and intuitions about political concepts; in the second, from reflection on our elemental convictions. The attempt to enlist these approaches under the heading of practice-dependence, then, can only breed confusion.

Vindicating views also have something to say about scope. Dworkin and Rawls (and Nagel), limit the scope of justice to certain types of institutions. The basis for the scope limitation is that political institutions need special principles to regulate them. They have certain characteristics that make principles of social justice pertinent to them. Those characteristics include the exercise of coercive power across members of a community on behalf of the community (Dworkin and Nagel), and the ability to assign socially recognised rights and duties (Rawls). ${ }^{88}$ Only communal-political institutions possess the feature, at least in the way it is interpreted in the theories. So, institutions without the feature are not appropriately characterised as just or unjust, and the relevant principles for these institutions must be ones directed at regulating the use of this power. The moral point of justice is the regulation of that power. However, the reason that this particular feature needs to be regulated is a moral one: it impinges in a special way on the value of individuals reasonably pursuing conceptions of the good. What is pertinent about the institutions, making their regulation a going concern, is not a pursued or practiced aim, but that their dispensing of social coercion can impinge on this value for individuals, and can do so differentially. This means that special principles, which address differential coercion, are needed to regulate the practice, principles that show us morally justifiable ways of distributing coercion across people in a society. If such principles exist, then that is the point, and conceptual limit, of social justice. The concept, in that sense, does not apply to practices without that feature: it has no rational point in those practices.

This is a vindicating approach because the fact that a practice has certain characteristics, such as social coercion, is due to the fact that people work together to collectively provide social coercion. Yet, the reason that the feature of coercion is the pertinent one, and that it, in particular, must be addressed in a practice that has that feature, is a moral reason. So, a feature of the practice is a relevant consideration as to what principles are relevant to the practice, but that is itself for a moral reason: a reason explaining why that feature is important and triggers moral considerations. The principles themselves are not formulated or constrained by reflection on socially accepted functional roles.

Of course, there are problems with the view that scope restrictions should follow authoritative coercive power and that this, in turns, limits justice to

88 - Thomas Nagel, "The Problem of Global Justice”; John Rawls, Political Liberalism, 108-109, $262 \mathrm{ff} ., 264-265$. 
political communities. ${ }^{89}$ Yet, there are other views with a scope thesis that have this kind of vindicating structure. For example, the "agency view" holds that principles of justice need to specify an agent of those principles, and specify clear duties for that agent. ${ }^{90}$ A candidate moral principle is incomplete without specifying an agent whose actions it guides, in the same way as a sentence is incomplete without a grammatical subject. For example, it is because there are agents with the power to assign socially recognised rights and duties that those agents are subject to moral principles of impartial social fairness. If justice consists in relations according those principles and the social values behind them, then it does not meaningfully apply between people who are not related by institutions with that kind of agency. It is the social agency that must act fairly to all, not the individuals whose duty is to contribute fairly to the operation of that agency. That is because requiring individuals to govern their lives impartially, according to equal concern or impartial distributive fairness towards others would, even if it were possible, be too demanding. All life decisions that had resource implications, including how many children to have or whether to undertake a personal cause, would need to be cleared as working positively towards a fair global distribution. It would undermine people's capacity to adopt distinctive life aims and commitments, and consequently to purse distinctive lives to any reasonable degree. ${ }^{91}$ In this case too, we have a moral reason for taking the concepts of justice and injustice to apply to certain contexts, and to regulate certain powers and relationships, and not others. There is no suggestion that the basis for this argument is the functional role of the institutions of a practice or a concept within a practice. ${ }^{92}$

\section{Conclusion: a level playing-field}

I have called the moral reasons for whether standards of justice or injustice apply to a specific context the conditions that trigger the application of moral principles. In the work of theorists mentioned in the last section, different triggering conditions are offered (coercion, power to assign rights and duties, ability to act on impartial social values). These are offered, in contrast to practice-dependence approaches, on the basis of moral, value-based arguments. In

89 - E.g. A. J. Julius, "Nagel's Atlas", Philosophy \& Public Affairs, 34/2 (2006), 176-192, 185 ff.

90 - Saladin Meckled-Garcia, "On the Very Idea of Cosmopolitan Justice", 246; also "International Law and the Limits of Global Justice", Review of International Studies, 37/5 (2011), 2073-2088.

91 - Saladin Meckled-Garcia, "On the Very Idea of Cosmopolitan Justice".

92 - In spite of this, the agency view too has been characterised as practice-dependent in the literature. This is, as I have argued above, due to an imprecise notion of what is distinctive about practice-dependence accounts. For example, Miriam Ronzoni, "The Global Order", 230, n. 5; Laura Valentini, "Global Justice and Practice-Dependence", 7, n. 25; Clara Brandi, "The World Trade Organisation as a Subject of Socioeconomic Justice", in Social Justice, Global Dynamics: Theoretical and Empirical Perspectives, eds. Ayelet Banai, Miriam Ronzoni and Christian Schemmel (Oxford: Routledge, 2011), 186; and Aaron James, Fairness in Practice, 25, n. 39. attribute the practice-dependence approach to Meckled-Garcia in "On the Very Idea of Cosmopolitan Justice", whereas this approach is explicitly rejected in that paper, at 251. 
some cases, the argument is simply based on the moral importance of the goods and costs that political institutions can marshal. In other cases, it is made on the basis of the type of agency involved and the kind of values that can reasonably guide different agents, given the burdens. These views are not inconsistent, therefore, with the justifiability constraint. The triggering conditions derive from the moral values in the theories. In that respect, the triggering conditions are up for critique in the way any other substantive part of a moral theory is open to critique: on the basis of value-based moral arguments.

I have not shown that the moral arguments for views with a restricted scope thesis are superior; although I have argued elsewhere that one of these views is superior to views without that kind of thesis. ${ }^{93}$ What I have shown is that one can rationally hold a restricted scope thesis, and argue for it on a basis that is consistent with the justifiability constraint. In this respect, the arguments in value-based views for the scope thesis are superior to practice-dependent accounts, which do not satisfy the justifiability constraint. I have also pointed out that where practice-dependence theorists do engage in arguing positively for an aptness claim, they are forced to appeal to substantive moral reasons and independent principles. This makes the practice-dependence approach not only problematic in terms of lacking adequate rational justification, but also an unnecessary diversion into "methodology" as way of arguing about scope restrictions on standards of justice. It is for those reasons a red herring in global justice debates.

\section{SALADIN MECKLED-GARCIA}

Saladin Meckled-Garcia is a founding director of the Institute for Human Rights, at University College London, as well as a Lecturer in Human Rights and Political Philosophy. He has been a Senior Research Fellow at University College London, and a Junior Research Fellow at the University of Birmingham. He has published in a variety of leading political philosophy and politics journals in areas including toleration and neutrality, equality and the market, international justice and international neutrality, human rights theory, interpretation and international law, international organisations and the scope of justice.

\section{ABSTRACT}

The Practice-Dependence Red Herring and Better Reasons for Restricting the Scope of Justice

In this paper, I make three points. The first is that there is indeed a distinctive approach to moral methodology, different from standard moral reasoning, that can be described as "practice-dependence". I argue that its distinctness lies in recommending an aptness claim, namely that moral principles for regulating social practices must be principles for better fulfilling the point of those practices, a point discoverable in shared understandings of the practice. Participants treat domestic political societies as having a different point to the practice of international relations. On this approach, then, different moral principles 
apply in each case: principles of distributive justice between citizens in the former and principles of cooperative fairness between states in the latter. My second point is that this approach fails, however, an important test which I call the justifiability constraint. Any formulation of a moral principle assigning rights and duties, benefits and burdens, to people should be justifiable to those persons by reference to a moral value. Yet, as I show, the practice-dependence view cannot offer any justification based on moral value for the aptness claim. My last point is that both endorsers and critics of practice-dependence have mistakenly attributed this approach to theorists who restrict the scope of justice on the basis of moral justification. Such views are, in fact, incompatible with the aptness claim given that they offer plausible independently derived moral grounds for restricting the scope of justice. They are also compatible with the justifiability constraint. For these reasons, I conclude that practice-dependence is a red herring for debates on global justice.

\section{RÉSUMÉ \\ La fausse piste de la dépendance aux pratiques et de meilleures raisons de restreindre la portée de la justice}

Dans cet article, j'avance trois thèses. La première est qu'il existe effectivement une approche spécifique de méthodologie morale, différente du raisonnement moral standard, qui peut être décrite comme «dépendance à la pratique ». Selon moi, sa spécificité repose sur l'affirmation selon laquelle les principes moraux servant à réguler les pratiques sociales doivent être les principes visant à remplir au mieux l'objet de ces pratiques, un objet qui peut être mis au jour à partir des compréhensions partagées de la pratique. Les participants considèrent que les sociétés politiques internes ont un objet différent de la pratique des relations internationales. Selon cette approche, par conséquent, différents principes moraux s'appliquent dans chacun des cas: des principes de justice distributive entre citoyens, d'une part, et des principes de coopération équitable entre États, de l'autre. Ma seconde thèse est que cette approche échoue néanmoins à passer un test important : la contrainte de justifiabilité. Toute formulation d'un principe moral qui assigne aux individus des droits et des devoirs, des bénéfices et des charges, devrait être justifiable visà-vis de ces personnes au regard d'une valeur morale. Pourtant, comme je le montre ici, l'approche par la dépendance aux pratiques ne peut offrir aucune justification du caractère approprié des principes qui soit fondée sur des valeurs. Ma dernière thèse consiste à noter que les défenseurs comme les détracteurs de la dépendance aux pratiques ont attribué cette approche à des théoriciens qui restreignent la portée de la justice sur la base d'une justification morale. Ces conceptions sont, en fait, incompatibles avec l'affirmation du caractère approprié des principes dans la mesure où la restriction de la portée de la justice repose sur un fondement moral indépendant. Elles sont aussi compatibles avec la contrainte de justifiabilité. Pour toutes ces raisons, je conclus que la dépendance aux pratiques est une fausse piste dans le débat sur la justice globale. 